\title{
Leadership and Cultural Change: Implications for Behavior Analysis
}

\author{
Ramona A. Houmanfar ${ }^{1}$ - Mark A. Mattaini $^{2}$
}

Published online: 27 April 2016

C) Association for Behavior Analysis International 2016

The Association for Behavior Analysis: International hosted the Seminar on Leadership and Culture Change in May 2014 to promote socially significant leadership practices at community and organizational levels, and to encourage additional behavioral research in this area. The presentations, beginning the day before the 40th annual convention and continuing as an organized set of talks during the Saturday and Sunday sessions, were divided into three subject-specific modules: organizations and the private sector, educational settings, and leadership and cultural change efforts. Due to the popularity of the program content, positive feedback, and large attendance, articles based on the seminar presentations were invited for publication in the Journal of Organizational Behavior Management (2015) and The Behavior Analyst.

Special thanks to program committee co-chairs Mark Alavosius and Timothy Ludwig for their valuable contribution to the design and implementation of the seminar. In addition, the program committee worked with coordinators for the Community, Social and Ethical Issues and Organizational Behavior Management program tracks who provided consistent support and assistance in integrating the seminar with the annual convention. We also thank the Organizational Behavior Management Network for their outstanding support throughout the process. Finally, we are grateful for the guidance, assistance, and hard work by the ABAI team, both on site and in the office.

The topics discussed at the seminar focused on ways behavior analysis offers powerful technology for changing behaviors and shaping the world's future. More specifically, social leaders were shown how a science of behavior can enhance the safety, ethicality, and effectiveness of organizations and institutions; and behavior analysts were challenged to adapt to an ever-shifting cultural landscape, and to turn their knowledge and skills into actions that could influence and improve social institutions.

Ramona A. Houmanfar ramonah@unr.edu

1 University of Nevada, Reno, Reno, NV, USA

2 University of Illinois at Chicago, Chicago, IL, USA 
Social responsibility served as a unifying theme throughout the presentations; the papers selected for this issue, and those included in the recent special issue of the Journal of Organizational Behavior Management (JOBM) on leadership and cultural change, are displayed in Table 1. The papers in the issue of $J O B M$ provide definitions and overview of associated characteristics associated with effective leadership (Krapfl, 2015; Geller, 2015) and provide discussion of ways contemporary confluences of organizational leadership, decision-making, and citizenship behavior often unintentionally contribute to the depletion of the world's resources; escalating health, education, and social crises; and community, societal, and cultural struggles to adapt to emerging global shifts (Alavosius, 2015; Houmanfar \& Mattaini 2015. Leadership and management practices in this context affect the wellbeing of organizational members in areas of their safety (Bogard, et al., 2015), health, financial security, and job satisfaction (Hantula, 2015; Houmanfar, et al., 2015) but also entail positive or negative impacts on consumer practices (Houmanfar, et al., 2015; Foxall, 2015) and collective community well-being in education and overarching cultural groups (Geller, 2015; Johnson, 2015; Baker, et al., 2015), obesity, cancer, safe or green driving, energy conservation, diversity-based health care, etc. (Houmanfar, et al., 2015; Foxall 2015; Baker, et al., 2015). In order to explore the emerging applications of behavior analysis to these challenges, the special issue of JOBM (2015) showcases emerging work by internationally recognized scholars on leadership and cultural change. The papers aid

Table 1 Special issue of Journal of Organizational Behavior Management on leadership and cultural change: table of contents

Houmanfar \& Mattaini (2015). Editorial-leadership and cultural change. Journal of Organizational Behavior Management, 35, 1-3.

Houmanfar R. A, Alavosius M. P, Morford, Z. H., Herbst S. A, \& Reimer R. (2015). Functions of organizational leaders in cultural change: financial and social well-being. Journal of Organizational Behavior Management, 35, 4-27.

Krapfl and\& Kruja (2015). Leadership and culture. Journal of Organizational Behavior Management, 35 , $28-43$.

Foxall (2015). Consumer behavior analysis and the marketing firm: bilateral contingency in the context of environmental concern. Journal of Organizational Behavior Management, 35, 44-69.

Bogard K., Ludwig T., Staats C., \& Kretchmer D. (2015) An industry's call to understand the contingencies involved in process safety: normalization of deviance. Journal of Organizational Behavior Management, $35,70-80$.

Hantula (2015). Job satisfaction: The management tool and leadership responsibility. Journal of Organiza tional Behavior Management, 35, 81-94.

Baker T., Schwenk T., Piasecki M,. Smith G. S., Reimer, D. Jacobs N., Shonkwiler G, Hagen J., Houmanfar R. A. (2015). Change in a medical school: a data-driven management of entropy. Journal of Organizational Behavior Management, 35, 95-122.

Grigsby (2015). Enhancing behavioral science knowledge and skills of 21st century leaders in academic medicine and science. Journal of Organizational Behavior Management, 35, 123-134.

Johnson (2015). Behavioral education in the 21st Century. Journal of Organizational Behavior Management, $35,135-150$.

Geller (2015) Seven life lessons from humanistic behaviorism: how to bring the best out of yourself and others. Journal of Organizational Behavior Management, 35, 151-170.

Alavosius (2015). The nurture effect: a book review. Journal of Organizational Behavior Management, 35 , $171-177$. 
organizations and leaders in creating new models of stewardship and discussing opportunities for innovation while adapting and responding to growing social upheaval, technological advances, and environmental concerns, as well as crises in the global economy, health, education, and environment.

The papers in this issue of The Behavior Analyst, while diverse, share a conviction that profound cultural change is necessary in this historical moment, and that the science of behavior (behavior analysis and behavioral systems analysis) has an opportunity - and a responsibility - to contribute to such change. Further, all of the papers recognize the essential role of leadership in initiating, shaping, and sustaining the construction of a more nurturing, just, and reinforcing society. The word "construction" is used intentionally here; all of these papers are in one way or another consistent with Goldiamond's (2002) insistence on a constructional approach to social problems. Behavior analysts are exceptional in their shared understanding that suppression of problems is seldom an effective approach, although such action is highly consistent with common relationally shaped behaviors and values in many contemporary cultures and societies. Most current societies (examples include the USA, the Middle East, and the European Union) are currently struggling with questions of both what should be constructed (e.g., a multicultural or homogeneous society - a value-based issue with empirical dimensions), and how to do so (e.g., how to construct a resource-light but more reinforcing culture - a technology question). Data to guide such decisions are increasingly available, as are technologies guided by selectionist science.

Surveillance systems tracking obesity rates, global warming, crime, drug use, gun deaths, and a host of other widespread social ills can illuminate the many social problems associated with cultural practices promoted by organizations, and the disturbing extent to which many of these are conjointly escalating in more than arithmetic ways. Such metrics can clarify important patterns for assessing the social responsibility of organizations (governmental, for profit and nonprofit) and their leaders in relation to present and future generations. In conducting such evaluations, behavior analytic researchers and practitioners also face the reality challenges of balancing the prosocial value of their interventions with financial, and often cultural, costs.

Offering guidance for decisions regarding construction of organizations and societies that respond in responsible ways to contemporary social problems offers challenges that behavior analysis cannot scientifically or ethically avoid. As highlighted in the special issue of JOBM on leadership and cultural change (2015), these challenges call for future work in behavior analysis, emphasizing the importance of establishing cultural practices that support prosocial behavior and reduce aversive conditions affecting individuals and cultural subgroups, while compatibly and sustainably strengthening societal institutions and systems. Global issues societies face will require multi-scaled solutions. As the papers in this issue suggest, our call is for exploration, testing, and development across a range of scales, from the most local to the global, with the goal of constructing nurturing environments that support the establishment and maintenance of prosocial behavior (Biglan, 2015; Houmanfar et al., 2015).

This is not to say that our science does not already have guidance to offer, albeit cautiously and with due humility. Consumptive behaviors are fundamental drivers of national and global realities, including conflicts over diminishing resources, global warming, economic obesity and other health problems and threats to wellbeing, and even human survival. At the cultural behavioral level, networks of interlocking 
behavioral contingencies (IBCs) shape and sustain the actions of organizational leaders (whether in the for-profit or other sectors) supporting present systemic arrangements (Houmanfar et al., 2015; Houmanfar, Rodrigues, \& Ward, 2010). As we complete this special issue, the primaries and presidential campaigns in the USA are in full force. Questions of transparency and social responsibility are being widely raised, but the discussions raise vast differences in preferred future directions. The science of behavior has reached a point where we can contribute to understanding and shaping cultural change addressing these challenges in socially responsible ways (Alavosius \& Mattaini, 2011; Alavosius, Newsome, Houmanfar, \& Biglan, 2016; Biglan, 2009; Biglan \& Glenn, 2013; Glenn, 1988; 2004; Glenn \& Malott, 2004; Malott \& Glenn, 2006; Houmanfar et al., 2010; Mattaini, 2013).

Central threads in behavioral accounts of leadership are communication between leaders and their followers (Daniels \& Daniels, 2005; Houmanfar, Rodrigues, \& Smith, 2009; Mawhinney, 1992; 2001; 2005; Mawhinney \& Ford, 1977) and how language plays a fundamental role in human behavior. In their role as guides and sources of motivation, leaders create verbal relations between the current and future state of the cultural group, between the future of the cultural group and its place in the future environment, and between current members' positioning and the future of cultural groups (Houmanfar, et al., 2010; Houmanfar \& Rodrigues, 2012). Effective leaders take into consideration the everevolving external environment and verbally evaluate potential adaptations the organization can make to those possible futures, while recognizing that other members of the cultural group are concurrently engaged in producing coherent verbal networks.

To increase the acceptance and therefore the effectiveness of their messages, effective leaders craft messages to suit the circumstances of the cultural group and its members. In crafting messages, leaders often also must account for conflicts among human values - between tendencies toward tolerance and tendencies toward extremism, between embracing diversity and the creation of ethnic purity (Houmanfar \& Rodrigues, 2012). Such conflicts have been shown to produce insensitivity to direct contingencies (e.g., insensitivity to the pain of others, and insensitivity to one's own pain) that can negatively impact group cohesion and team work. Our challenge is to help leaders understand the damaging nature of such conflicts and promote the utilization of verbal networking systems that can prevent their destructive effect on organizational effectiveness and survival.

The challenges contemporary leaders face are immense. Leadership in social responsibility can be costly for those involved, who are often tasked with constructing organizational cultures that are inconsistent with broader current cultural contingencies and values. Visionary leaders are being asked to lay the foundation for critical cultural cusps that have not yet emerged. At its current state of development, the science of behavior has developed some knowledge that can support such pioneers for sustainability and justice. Behavior analysis and behavioral systems analysis, in collaboration with other concerned disciplines and groups (e.g., political science, social psychology, sociology, health and communication, etc.) may have the potential to contribute to the design of new repertoires and contingency arrangements consistent with culture-wide nurturing of prosocial behaviors and cultural practices. But as the papers in this issue also demonstrate, much more work is needed, hard work that will stretch the boundaries of how behavior analysis is defined, as we act to bring intentional science into the heart of organizational and cultural evolution. 


\section{References}

Alavosius, M. P. (2015). The nurture effect: a book review. Journal of Organizational Behavior Management, $35,171-177$.

Alavosius, M. P., \& Mattaini, M. A. (2011). Editorial: behavior analysis, sustainability, resilience, and adaptation. Behavior and Social Issues, 20, 1-5.

Alavosius, M. P., Newsome, W. D., Houmanfar, R., \& Biglan, A. (2016). A functional contextualist analysis of the behavior and organizational practices relevant to climate change. In R. D. Zettle, S. C. Hayes, D. Barnes-Holmes, \& A. Biglan (Eds.), Handbook of contextual behavior science (pp. 513-530). NY: Wiley.

Baker, T., Schwenk, T., Piasecki, M., Smith, G. S., Reimer, D., Jacobs, N., et al. (2015). Change in a medical school: a data-driven management of entropy. Journal of Organizational Behavior Management, 35, 95-122.

Biglan, A. (2009). The role of advocacy organizations in reducing negative externalities. Journal of Organizational Behavior Management, 29, 215-230.

Biglan, A. (2015). The nurture effect: how the science of human behavior can improve our lives and our world. Oakland, CA: New Harbinger.

Biglan, A., \& Glenn, S. S. (2013). Toward prosocial behavior and environments: behavioral and cultural contingencies in a public health framework. In G. J. Madden (Ed.), APA Handbook of Behavior Analysis (pp. 255-275). Washington, DC: American Psychological Association.

Bogard, K., Ludwig, T., Staats, C., \& Kretchmer, D. (2015). An industry's call to understand the contingencies involved in process safety: normalization of deviance. Journal of Organizational Behavior Management, $35,70-80$.

Daniels, A. C., \& Daniels, J. E. (2005). Measure of a leader. Atlanta, GA: Performance Management Publications.

Foxall, G. R. (2015). Consumer behavior analysis and the marketing firm: bilateral contingency in the context of environmental concern. Journal of Organizational Behavior Management, 35, 44-69.

Geller, S. E. (2015). Seven life lessons from humanistic behaviorism: how to bring the best out of yourself and others. Journal of Organizational Behavior Management, 35, 151-170.

Glenn, S. S. (1988). Contingencies and metacontingencies: toward a synthesis of behavior analysis and cultural materialism. The Behavior Analyst, 11, 161-179.

Glenn, S. S. (2004). Individual behavior, culture, and social change. The Behavior Analyst, 27, 133-151.

Glenn, S. S., \& Malott, M. M. (2004). Complexity and selection: implications for organizational change. Behavior \& Social Issues, 13, 89-106.

Goldiamond, I. (2002). Toward a constructional approach to social problems: ethical and constitutional issues raised by applied behavior analysis. Behavior and Social Issues, 11, 108-197.

Reprinted from Behaviorism, 2 (1974), 1-84.

Grigsby, K. R. (2015). Enhancing behavioral science knowledge and skills of 21 st century leaders in academic medicine and science. Journal of Organizational Behavior Management, 35, 123-134.

Hantula, D. (2015). Job satisfaction: the management tool and leadership responsibility. Journal of Organizational Behavior Management, 35, 81-94.

Houmanfar, R., Alavosius, M. P., Morford, Z. H., Reimer, D., \& Herbst, S. A. (2015). Functions of organizational leaders in cultural change: financial and social well-being. Journal of Organizational Behavior Management, 35, 4-27.

Houmanfar, R., Mattaini, M. A. (Eds.). (2015). Special issue on leadership \& cultural change. Journal of Organizational Behavior Management, 25, 1-3.

Houmanfar, R., \& Rodrigues, N. J. (2012). The role of leadership and communication in organizational change. Journal of Applied Radical Behavior Analysis, N1, 22-27.

Houmanfar, R. A., Rodrigues, N. J., \& Smith, G. S. (2009). Role of communication networks in behavioral systems analysis. Journal of Organizational Behavior Management, 29, 257-275.

Houmanfar, R. A., Rodrigues, N. J., \& Ward, T. A. (2010). Emergence \& metacontingency: points of contact and departure. Behavior and Social Issues, 19, 78-103.

Johnson, K. (2015). Behavioral education in the 21st Century. Journal of Organizational Behavior Management, 35, 135-150.

Krapfl, J. E., \& Kruja, B. (2015). Leadership and culture. Journal of Organizational Behavior Management, $35,28-43$.

Malott, M. E., \& Glenn, S. S. (2006). Targets of intervention in cultural and behavioral change. Behavior and Social Issues, 15, 31-56. 
Mattaini, M. (2013). Strategic nonviolent power: the science of Satyagraha. Edmonton, AB: athabasca University Press. (Also available online at http:/www.aupress.ca/books/120224/ebook/99Z_Mattaini_ 2013-Strategic_Nonviolent_Power.pdf.

Mawhinney, T. C. (1992). Evolution of organizational cultures as selection by consequences: the Gaia hypothesis, metacontingencies, and organizational ecology. In T. C. Mawhinney (Ed.), Organizational Culture, Rule-Governed Behavior and Organizational Behavior Management (pp. 1-26). New York: The Haworth Press, Inc.

Mawhinney, T. C. (2001). Organization-environment systems as OBM intervention context: minding your metacontingencies. In L. J. Hayes, J. Austin, R. Houmanfar, \& M. C. Clayton (Eds.), Organizational Change (pp. 137-166). Reno, NV: Context Press.

Mawhinney, T. C. (2005). Effective leadership in superior-subordinate dyads: theory and data. Journal of Organizational Behavior Management, 25(4), 37-77.

Mawhinney, T. C., \& Ford, J. D. (1977). The path goal theory of leader effectiveness: an operant interpretation. Academy of Management Review, 2, 398-411. 